\title{
Evaluation of 100 most cited research articles on African medicinal plants
}

\author{
Kunle Okaiyeto \& Oluwafemi O. Oguntibeju* \\ Phytomedicine and Phytochemistry Group, Oxidative Stress Research Centre, Department of Biomedical Sciences, Faculty of Health and \\ Wellness Sciences, Cape Peninsula University of Technology, Bellville 7535, South Africa \\ *Email: oguntibejuo@cput.ac.za
}

\section{ARTICLE HISTORY}

Received: 27 November 2020

Accepted: 10 March 2021

Published: 01 April 2021

\section{KEYWORDS}

African medicinal plant

Bibliometric analysis

100 most cited articles

Collaboration network

\section{ABSTRACT}

The mission for drug discovery and development has prompt researchers to scientifically validate the therapeutic uses of medicinal plants available worldwide of which, African medicinal plants serve as a great reservoir. Despite the extensive work in the field of medicinal plants of African origin, however, bibliometric report on the work conducted on African medicinal plants is scarce and hence, the present study aimed at evaluating the top 100 most cited articles on medicinal plant wealth of Africa. The literature data used for the bibliometric analysis was explored from Web of Science (WoS) while Rstudio and VOSviewer software were used for data analysis and collaboration network visualization, respectively. The most prolific authors were Van Staden J, Jager AK, Teklehaymanot T whereas, the top 3 journals were Journal of Ethnopharmacology, Journal of Ethnobiology and Ethnomedicine and South African Journal of Botany. Most cited journals were Journal of Ethnopharmacology, Phytochemistry, Phytotherapy Research. The topmost institutions in terms of the number of articles were the University of KwaZulu-Natal, University of Addis Ababa and Pretoria. South Africa was the most cited country followed by Nigeria. Single country publications dominated the field and therefore, multiple country collaboration should be a focus of social networks among the researchers in the field.

\section{Introduction}

African traditional plant-based medicines are referred to as indigenous knowledge, beliefs, practices, skills, philosophies, ideas or theories associated with different cultures explored in the treatment or management of various human diseases with the aid of herbs mixtures (1). From time immemorial, herbal medicines have been playing a significant role in the well-being of people living in developing countries around the world, especially those in the African countries (2). The World Health Organization (WHO) reported that $80 \%$ of developing countries depend on traditional medicine for therapeutic purposes (3). These plants have been reported to possess several therapeutic potentials against various human deadly ailments $(4,5)$. Traditional medicine practices have been embraced by other populaces beyond its original indigenous culture, which is now referred to as complementary or alternative medicine $(\mathrm{CAM})(3,6)$. The efficacy of herbal medicines over synthetic drugs could be attributed to the fact that herbal mixtures comprise numerous bioactive compounds that possibly have additive or synergetic effects to enhance their therapeutic uses $(7,8)$. Bioactive compounds are referred to as secondary metabolites and their presence in plants is highly beneficial such that they serve as defensive agents against predators, pests, diseases and protect them from the harsh environmental conditions (8).

Several factors influence the patronage of herbal medicines. These factors include but not limited to the following; self medication, the cost-effectiveness of herbal medicines based on the standard of living of the people living in the developing countries, ease accessibility of herbal mixtures, a belief of people due to the failure of synthetic drugs to treat some diseases that consequently lead to death, increased incidence of multidrug-resistant infections, an adverse effect associated with prolonged use of synthetic drugs, fear of confidentiality of their health problem information

(c) Okaiyeto \& Oguntibeju (2021). This is an open-access article distributed under the terms of the Creative Commons Attribution License, which permits unrestricted use, distribution and reproduction in any medium, provided the original author and source are credited (https://creativecommons.org/licenses/by/4.0/).

To cite this article: Okaiyeto K, Oguntibeju O O. Evaluation of 100 most cited research articles on African medicinal plants. Plant Science Today. 2021;8(2):340-351. https://doi.org/10.14719/pst.2021.8.2.1043 
in the modern health sector, belief of people that herbal medicines are better than orthodox medicines, the fear of wrong diagnosis or treatment from some inexperienced medical practitioners, improve in herbal mixture due to integration of modern ideas (8, 9).

The utilization of herbal mixture as a major part of the African traditional healthcare system is may be due to the oldest, and the most assorted of all therapeutic systems. In many parts of rural Africa, traditional healers prescribing medicinal plants are the most easily accessible and affordable health resources available to the local community and the only therapy that exists $(11,12)$. Despite the numerous advantages associated with herbal medicine, however, the general belief or notion of people that herbal mixtures are safe with no adverse effects is fallacious and misleading (13). The reality is that the issue concerning their safety cannot be completely ignored or neglected as most herbal practitioners are not licensed. Therefore, the quality, standard and safety of herbal medicines have become a major concern to public health (14).

Over the years, these herbal folklores have been identified as the epicentre of drug discovery $(4,15$, 16). The use of herbal medicine has become mainstream in developed countries and there is this notion that herbal products promote healthier living $(17,18)$. The therapeutic uses of herbal medicines could be attributed to their potentials to protect sensitive organs that are easily prone to oxidative damaged initiated by the cascade of events that lead to the generation of different types of reactive oxygen species (ROS) molecules in the biological system especially the macromolecules such as proteins, DNA and lipids (19). ROS generation is an aerobic process that is essential for maintaining normal cellular functions such as signal transduction (20). The level of ROS generated depends on the extent of oxidative challenges to these aforementioned macromolecules and this could be one of the major factors responsible for oxidative-induced diseases and ageing (21). Although, synthetic drugs are commonly used, the high cost of these drugs and adverse effects on their long use has necessitated the quest for searching for alternative option (22). Several African plants such as Aloe ferox (23), Agathosma betulina (24), Aspalathus linearis (25), Harpagophytum procumbens (26), Siphonochilus aethiopicus (27), Hypoxis hemerocallidea (28) have been validated for their folkloric therapeutic uses, however, studies revealing the qualitative and quantitative analysis of the extent of research in the field have been relatively scarce.

On the other hand, bibliometric analysis is a statistical method used to monitor research trends of researchers, institutions, countries, journals and to determine hotspots of research or future direction (29-31). It uses extracted data from the literature to analyse publications quantitatively and qualitatively (32). Its applications in various fields have gained immense popularity over the years. Bibliometric analysis has been successfully explored in assessing research productivity in diabetes (33-35), tuberculosis (36), rehabilitation of spinal cord injury (37), road traffic injuries (38), malaria $(39,40)$, food borne disease (41), sustainable livelihood (42), Plesiomonasrelated research (43) and Cholera (44).

In spite the extensive work on African herbal medicines, however, attention has not been paid to quantify the research outputs in the field. Therefore, a study of this kind is highly imperative. As a result, this present study is designed to evaluate the 100 most cited articles on African medicinal plant research.

\section{Materials and Methods}

\section{Data collection}

WoS was used to retrieve publications on 100 most cited articles on African medicinal plant research. The knowledge of search expressions for scientific papers is important for text visibility. We used the title search with these keywords (medicinal plants/phytomedicines/herbal folkloric/herbal product/phytochemical/traditional complementary medicine/African Traditional Medicine/TCM OR herbal) and Science Citation Index Expanded (SCIExpanded) was chosen because of the subject under study. The study period was from 1990 to 2019 and focused on only the research articles written in English. The SCI-Expanded database is the most comprehensive and frequently used data source in bibliometrics for reviewing high-quality publications and for assessing scientific development, current hotspots and future directions $(45,46)$. We selected the top 100 among these articles and saved with Bibtex format in a notepad for analysis $(47,48)$.

\section{Data analysis and visualization}

We exported the retrieved data to Rstudio (version 3.6.2) and analysed using the bibliometrix package for annual scientific production over the year, most prolific authors, most relevant journals and occurrence keywords (49). VOSviewer software (version 1.6.14) was explored to visualise collaboration networks that exist among authors, institutions and countries that published the 100 most cited papers on African medicinal plant research (50).

\section{Results and Discussion}

\section{Main information about the data collection}

Publication, as a central part of scientific research, is a significant indicator for research contribution (50). In the present study, 100 most cited articles on African medicinal plants research were investigated. Research productivity was assessed by the quantity of publications while the total number of citations was used to identify the most influential articles in the field (35). However, "the big question about the benefits of effective scientific communication is that the growing number of journals' publications and the tendency to make them available in digital media, how can scientific articles reach the largest number of readers and specifically, the audience who will find the work most salient? (51). The need of this document to be found easily in the databases of both 
printed and digital texts is pre-eminent among the several factors that contribute to the readers' search for articles". As a result, we explored some keywords on the subject to extract data from WoS especially those indexed in SCI-Expanded. Table 1 depicts information about 100 most cited research articles on African medicinal plant research. Our search span over 30 years from 1990 to 2019 and 100 articles were published from 28 sources and authored by 291

Table 1. Main information about the collection of 100 most cited articles on African medicinal plant research between 1990 and 2019.

\begin{tabular}{|c|c|}
\hline Description & Results \\
\hline "Timespan" & 1993:2014 \\
\hline "Sources (Journals, Books, etc) & 28 \\
\hline “Documents” & 100 \\
\hline “Average years from publication” & 14.5 \\
\hline “Average citations per documents" & 107 \\
\hline “Average citations per year per doc” & 7.147 \\
\hline "References” & 3167 \\
\hline \multicolumn{2}{|l|}{ “DOCUMENT TYPES” } \\
\hline “Article” & 100 \\
\hline \multicolumn{2}{|l|}{ “DOCUMENT CONTENTS” } \\
\hline “Keywords Plus (ID)” & 305 \\
\hline “Author's Keywords (DE)” & 318 \\
\hline \multicolumn{2}{|l|}{ “AUTHORS” } \\
\hline “Authors” & 291 \\
\hline “Author Appearances” & 355 \\
\hline "Authors of single-authored documents" & 5 \\
\hline "Authors of multi-authored documents" & 286 \\
\hline \multicolumn{2}{|l|}{ “AUTHORS COLLABORATION” } \\
\hline "Single-authored documents" & 5 \\
\hline "Documents per Author" & 0.344 \\
\hline “Authors per Document” & 2.91 \\
\hline "Co-Authors per Documents" & 3.55 \\
\hline "Collaboration Index" & 3.01 \\
\hline
\end{tabular}

researchers, of which, authors of single-authored documents were 5 and authors of multi-authored documents were 286. All the articles have average years from the publication of 14.5, an average citations/document of 107, and an average citations/year/document of 7147 . The whole 100 research articles comprising 3167 references with keywords Plus and author's keywords of 305 and 318, respectively. The analysis also revealed research collaboration that exists between researchers that published the top 100 most cited articles on African medicinal plants with documents per author of 0.344 and authors per document 2.91, co-authors/document of 3.55. Overall, the annual growth rate was $3.53 \%$, and the collaboration index (CI) among the implicated researchers on the subject was 3.01. Thus, the $C I$ value shows strong collaboration among the researchers that published the articles under study. However, it is difficult to determine which type of collaboration that exists between the researchers, may be such that exists among researchers from different institutions within a country or collaborations across the borders that involves international researchers through different countries. Interestingly, such an analysis that would reveal the collaboration is imperative and is part of the subsequent analyses. Furthermore, it is interesting to note that the 100 top-cited articles were recorded between 1993 and 2014; which means recent research from 2015 to 2019 had no such citations impact to be counted among the studied articles. These findings corroborate with the reports of other studies which stated that the age of publication has a remarkable effect on its visibility and citations $(42,52)$.

\section{Most cited documents}

The most cited documents on the African medicinal plant research articles were investigated and the results are represented in Table 2. The top 5 documents among those listed in Table 2 were authored by Edeoga HO (2005) published in Afr J Biotechnol with 587 citations followed by Soliman KM (2002) in Food Chem Toxicol (326 citations), Rabe $\mathrm{T}$ (1997) in J Ethnopharmacol (259 citations), Eddouks M (2002) in J Ethnopharmacol (254 citations), Clarkson C (2004) in J Ethnopharmacol (242 citations). It is of paramount important to emphasize that the citations in the present study is only based on the WoS analysis and excluded citations from other databases, hence, the articles citations might not represent the whole citations that these articles have received over the year. For example, if you compare the citations of these articles in other databases, they might be higher than those presented in this study. This implies that citations associated to an article vary with databases such as WoS, Scopus, PubMed, Google scholar, etc.

\section{Annual scientific production}

The top 100 most cited articles on African medicinal plant research were evaluated in the present study based on the information retrieved from the WoS database, specifically those indexed in SCI-Expanded. One article was recorded in 1993, 1995, 1996 and 1998; unfortunately, no single article was recorded in 1994 (Fig. 1). Five (5) articles were reported in 1999, and 7 articles in 2000. The number of articles each year varies, and we reported the highest number of articles in 2007. Overall, 8 articles representing 8\% each were recorded in 2006, 2008, 2009 and 2010, which amount to $32 \%$ of the 100 articles for 4 years. In general, the number of articles $(n=12)$ recorded in the early year from 1993 to 1999 was relatively low as compared to those 2000 to 2006 ( $n=38$ ). However, the research outputs seem to be increased with time. Research only achieves its goal when it is shared, i.e. when an author finds the audience who values his ideas, findings. Today, reader interest can be measured in terms of the number of views that an article receives. Furthermore, the validation of a research, its legitimization and acknowledgement, depends on the reader's judgement related to the text, which can be measured by the rate and, most importantly, by its citation in other works (51). 
Table 2. Most global cited documents among the top 100 articles on African medicinal plant research.

\begin{tabular}{|c|c|c|c|}
\hline Articles & Title & TC & $\begin{array}{l}\text { TC per } \\
\text { Year }\end{array}$ \\
\hline Edeoga HO, 2005, Afr J Biotechnol & "Phytochemical constituents of some Nigerian medicinal plants" & 587 & 36.69 \\
\hline Soliman KM, 2002, Food Chem Toxicol & $\begin{array}{l}\text { "Effect of oil extracted from some medicinal plants on different } \\
\text { mycotoxigenic fungi" }\end{array}$ & 326 & 17.16 \\
\hline Rabe T, 1997, J Ethnopharmacol & $\begin{array}{l}\text { "Antibacterial activity of South African plants used for medicinal } \\
\text { purposes" }\end{array}$ & 259 & 10.79 \\
\hline Eddouks M, 2002, J Ethnopharmacol & $\begin{array}{l}\text { "Ethnopharmacological survey of medicinal plants used for the treatment } \\
\text { of diabetes mellitus, hypertension and cardiac diseases in the south-east } \\
\text { region of Morocco (Tafilalet)" }\end{array}$ & 254 & 13.37 \\
\hline Clarkson C, 2004, J Ethnopharmacol & $\begin{array}{l}\text { "In vitro antiplasmodial activity of medicinal plants native to or } \\
\text { naturalised in South Africa" }\end{array}$ & 242 & 14.24 \\
\hline Ayoola GA, 2008, Trop J Pharm Res & $\begin{array}{l}\text { "Phytochemical screening and antioxidant activities of some selected } \\
\text { medicinal plants used for malaria therapy in Southwestern Nigeria" }\end{array}$ & 221 & 17.00 \\
\hline Jouad H, 2001, J Ethnopharmacol & $\begin{array}{l}\text { "Ethnobotanical survey of medicinal plants used for the treatment of } \\
\text { diabetes, cardiac and renal diseases in the North centre region of } \\
\text { Morocco (Fez-Boulemane)" }\end{array}$ & 215 & 10.75 \\
\hline Jager AK, 1996, J Ethnopharmacol & $\begin{array}{l}\begin{array}{l}\text { "Screening of Zulu medicinal plants for prostaglandin-synthesis } \\
\text { inhibitors" }\end{array} \\
\end{array}$ & 213 & 8.52 \\
\hline $\begin{array}{l}\text { Teklehaymanot T, 2007, J Ethnobiol } \\
\text { Ethnomed }\end{array}$ & $\begin{array}{l}\text { "Ethnobotanical study of medicinal plants used by people in Zegie } \\
\text { Peninsula, Northwestern Ethiopia" }\end{array}$ & 202 & 14.43 \\
\hline Lin J, 1999, J Ethnopharmacol & $\begin{array}{l}\text { "Preliminary screening of some traditional Zulu medicinal plants for anti- } \\
\text { inflammatory and anti-microbial activities" }\end{array}$ & 171 & 7.77 \\
\hline Mcgaw LJ, 2000, J Ethnopharmacol & $\begin{array}{l}\text { "Antibacterial, anthelmintic and anti-amoebic activity in South African } \\
\text { medicinal plants" }\end{array}$ & 166 & 7.90 \\
\hline Giday M, 2009, J Ethnopharmacol & $\begin{array}{l}\text { "Medicinal plants of the Meinit ethnic group of Ethiopia: an } \\
\text { ethnobotanical study" }\end{array}$ & 159 & 13.25 \\
\hline Kelmanson JE, 2000, J Ethnopharmacol & "Zulu medicinal plants with antibacterial activity" & 158 & 7.52 \\
\hline $\begin{array}{l}\text { Aiyegoro OA, 2010, BMC Complement } \\
\text { Altern Med }\end{array}$ & $\begin{array}{l}\text { "Preliminary phytochemical screening and in vitro antioxidant activities } \\
\text { of the aqueous extract of Helichrysum longifolium DC" }\end{array}$ & 154 & 14.00 \\
\hline Dold AP, 2002, S Afr J Sci & $\begin{array}{l}\text { "The trade in medicinal plants in the Eastern Cape Province, South Africa: } \\
\text { Research article" }\end{array}$ & 148 & 7.79 \\
\hline Atmani D, 2009, Food Chem & $\begin{array}{l}\text { "Antioxidant capacity and phenol content of selected Algerian medicinal } \\
\text { plants" }\end{array}$ & 137 & 11.42 \\
\hline El-Hilaly J, 2003, J Ethnopharmacol & $\begin{array}{l}\text { "Ethnobotanical studies and economic evaluation of medicinal plants in } \\
\text { Taounate province (Northern Morocco)" }\end{array}$ & 136 & 7.56 \\
\hline Matu EN, 2003, J Ethnopharmacol & $\begin{array}{l}\text { "Antibacterial and anti-inflammatory activities of some plants used for } \\
\text { medicinal purposes in Kenya" }\end{array}$ & 132 & 7.33 \\
\hline Mathabe MC, 2006, J Ethnopharmacol & "Antibacterial activities of medical plants" & 129 & 8.60 \\
\hline Ajasa A, 2004, Food Chem & $\begin{array}{l}\text { "Heavy trace metals and macronutrients status in herbal plants of } \\
\text { Nigeria" }\end{array}$ & 129 & 7.59 \\
\hline
\end{tabular}

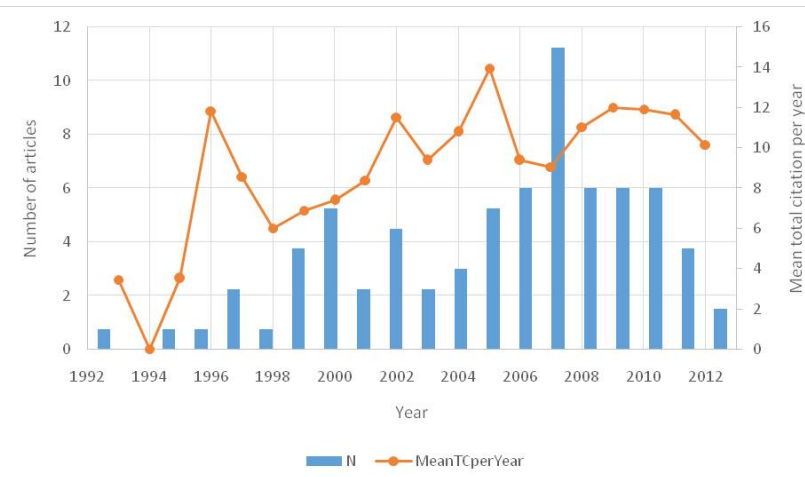

Fig. 1. Annual production on top 100 most cited articles on African medicinal plant research between 1990 and 2019.

Therefore, the mean total citations of these articles were also assessed in the present study, a varying citation was observed over the years, and the highest citations were received in 2005. The lowest citations were recorded in 1993. Usually, the age of publication influences the citation of an article (52); nevertheless, the reverse is the case in the present study as we observed low citations in 1993 and 1995. Several factors could result into this observation and among such factors are an increase in the interest of researchers in the field in the recent time and this could increase the research outputs with quality papers that attracted attention or research collaboration with an exchange of resources, new techniques, ideas and research funding could influence productivity and scientific impact. Another important factor that calls for the quest of medicinal plant research is the adverse effects associated with the extensive use of conventional drugs to treat different human infections and diseases $(4,15)$. Medicinal plant research has gained popularity among African researchers owing to their many advantages such as cost-effectiveness, availability, potency and simplicity (53). The bioactive compounds of these plants have identified to be responsible for the various biological activities and these have become the interest of African researchers to identify the most active compounds that could lead to drug development (15). In recent times, several studies have been conducted to investigate the mechanism of action of pure compounds isolated from African medicinal plants (54-57). Therefore, it is noteworthy to emphasize that all these activities on medicinal plants have increased research outputs significantly and with a prime prospect in competing with other researchers globally.

\section{Most prolific authors}

The most active authors among the researchers that authored the 100 topmost cited articles on African medicinal plant research were investigated and the results are represented in Fig. 2a. The top 5 among these authors were Van Staden J ( $n=15)$, Jager AK ( 

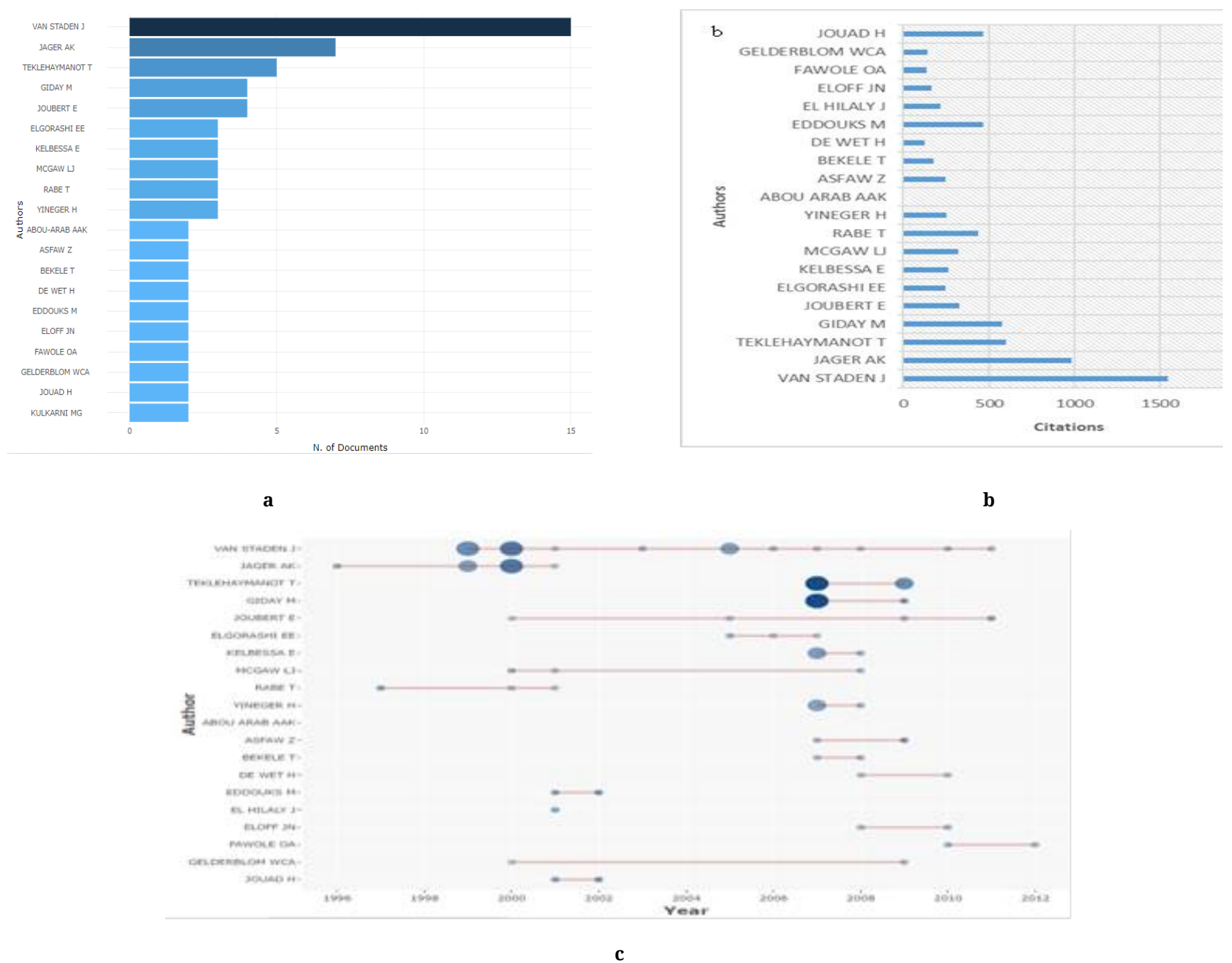

Fig. 2. Most prolific authors in the 100 most cited articles on African medicinal plant research. Prolific authors based on the number of articles (a), most cited authors (b) and authors' active period (c).

= 7), Teklehaymanot $T(n=5)$, Giday M ( $(n=4)$, Joubert $E(n=4)$. In terms of authors-fraction, Van Staden J was ranked highest with articles fractionalized of 4.4667 followed by Teklehaymanot $\mathrm{T}$ (2.5), Jager AK (1.9), Giday M (1.5) and Tabuti JRS (1.3333) (Supplementary Table S1). Likewise, authors' impact was assessed and Van Staden J was the most impactful author with h-index of 15 with 1545 total citations and publication start year from 1999. The second ranked author was Jager AK (h-index of 7 and 982 total citations from 1996), Teklehaymanot T (hindex of 5 and 601 total citations from 2007), Giday $\mathrm{M}$ (h-index of 4 and 576 total citations from 2007) and Joubert E (h-index of 4 and 330 total citations from 2000) (Supplementary Table S2). Because citation accumulates with time, papers published earlier have a higher probability of receiving more citations than the new ones, making this an important issue when the citation count is used for the ranking of individual papers (58). The h-index is regarded as an optimum measure to evaluate the impact of scientific research and is proposed as an alternative to other bibliometric indicators (59). According to one report (60), "the index of $\mathrm{H}$ means that $\mathrm{H}$ of a scientist's or a country's publications have been cited in other publications at least $\mathrm{H}$ times each". This statement was supported by the report (61) which further argued that "an $\mathrm{H}$-index reflects both the number of publications and the number of citations per publication". Furthermore, we also carried out an analysis to monitor the research activity of the authors over time from the 100 most cited articles on African medicinal plants and we observed that Van Staden J was consistently active from 1999 to 2011 whereas Jager AK was active from 1996 to 2001. Teklehaymanot $\mathrm{T}$ and Giday $\mathrm{M}$ were only active between 2007 and 2009 (Fig. 2c). The number of citations received in a particular year determines the size of the sphere. Knowing the characteristics related to the high citation index of an article is important, not only to authors, but also to the publishing journals, in order to "improve the journal's credibility, relevance and financial independence" (62).

\section{Relevant sources}

The top 100 cited articles on African medicinal plantrelated research were published in 28 journals (Fig. 3a). The topmost cited sources (journals) in term of the number of articles was Journal of Ethnopharmacology ( $n=56$ [56\%]) followed by Journal of Ethnobiology and Ethnomedicine $(n=6$ 


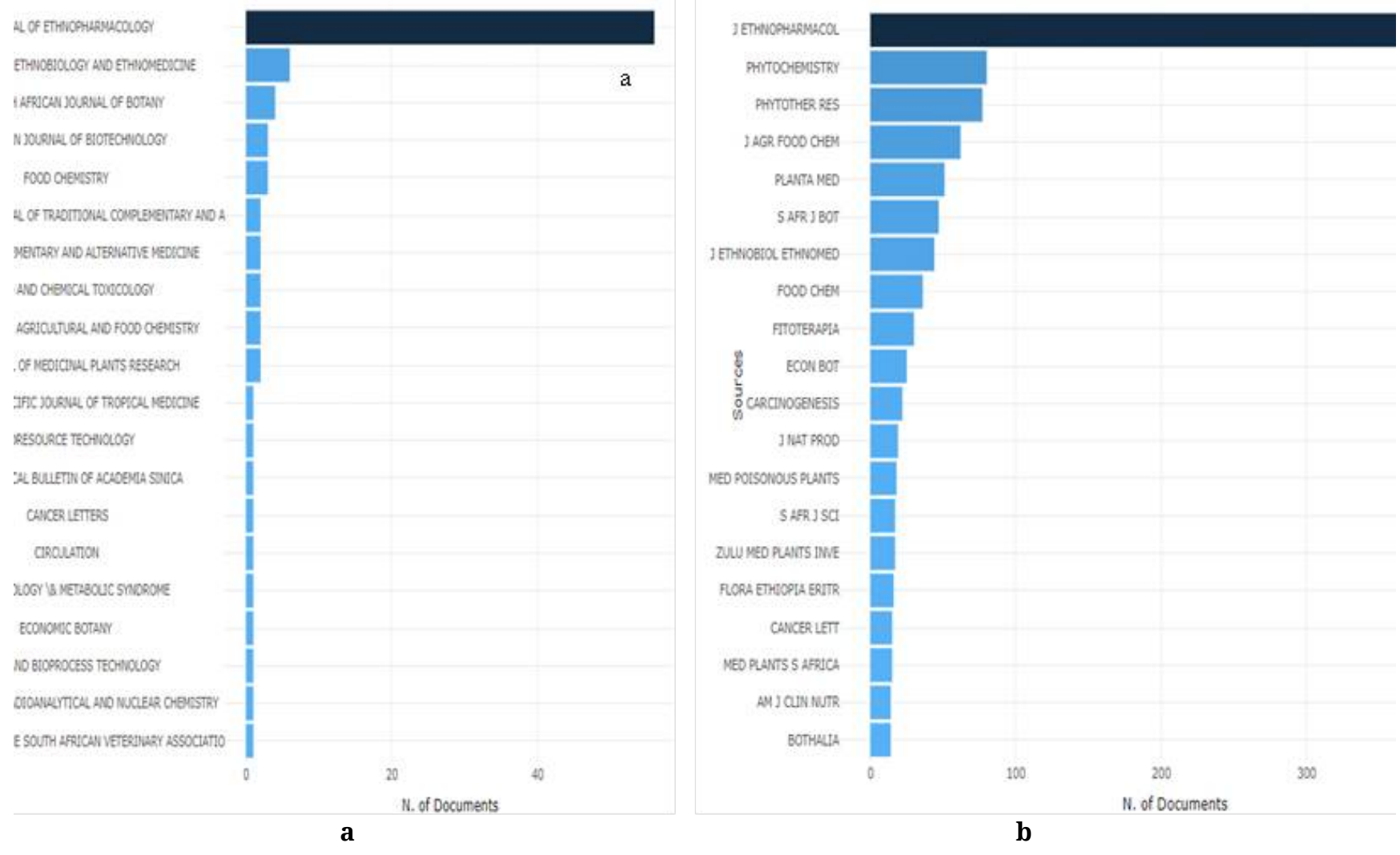

Fig. 3. 100 most cited sources on African medicinal plant research.

[6\%]), South African Journal of Botany ( $\mathrm{n}=4[4 \%])$, African Journal of Biotechnology $(n=3[3 \%])$ and Food Chemistry ( $\mathrm{n}=3[3 \%]$ ). It is surprising that above half of the 100 most cited articles were published in the Journal of Ethnopharmacology. Overall, $72 \%$ of the most cited articles retrieved from SCI-Expanded were recorded from the top 5 journals as shown in Fig. 3a. Likewise, we also evaluated the most locally cited journals from the reference list of these 100 articles and we have that Journal of Ethnopharmacology was the most referenced journal with 419 citations followed by Phytochemistry $(\mathrm{n}=$ 80), Phytotherapy Research ( $\mathrm{n}=77)$, Journal of Agricultural and Food Chemistry (62), Planta Medica (51) (Fig. 3b).

\section{Most relevant institutions and countries}

Fig. 4a represents the results of the most relevant institutions on 100 topmost cited articles on African medicinal plant research. Among these institutions included University of KwaZulu-Natal (South Africa) ( $n=28$ articles), followed by University of Addis Ababa with 22 articles, University of Pretoria (South Africa) $(n=15)$, Makerere University (Uganda) $(n=$ 12). National research Centre (Egypt) had 11 articles while University of Zululand (South Africa) had 9 articles and Obafemi Awolowo University (Nigeria) and University of Ibadan (Nigeria) had 8 articles each. Cairo University (Egypt), Tshwane University of Technology, University of Limpopo, University of Nigeria, Stellenbosch University and University of Witwatersrand had 6 articles each and Jimma University, Michael Okpara University of Agriculture, University of Khartoum, University of Lagos had 5 articles. The institution that encourages research also shares the credits of this merit. Social prestige, reflecting their successful academic outputs, increases the likelihood of receiving funding and resources for executing new projects (63).

Similarly, we also investigated the countries/regions distribution of these articles and we observed that South Africa was ranked the highest with 42 articles which representing $42 \%$ of the total article under investigation. Nigeria, Ethiopia and Egypt were 17, 14 and 7, respectively (Fig. 4b). It is surprisingly that only Egypt was involved in multiple country publication (MCP) $(n=1)$ and research collaboration in the remaining countries was only based on single country population. In addition, countries' citations were also assessed and it is amazing that South Africa was the most cited country ( $\mathrm{n}=4328$ citations) with an average article citation of 103, followed by Nigeria (2123 citations) with average article citation of 124.9, Ethiopia ( $\mathrm{n}=$ 1425) with average article citations of 101.8 (Fig 4c).

\section{Co-occurrence keywords}

Co-occurrences of title terms indicate the number of times two terms occur together in a set of documents (64). Effective scientific writing has attracted huge attention in recent times (51). Keywords usage has been regarded as one of the key criteria for paper submission in a journal since the mid-1990s. Wellcrafted keywords assist researchers in the collection of literature for systematic reviews. Keywords can be classified into three groups such as specific, intermediate and general (65). For example, a researcher who is interested in a particular issue, problem or event that has been reported in the 

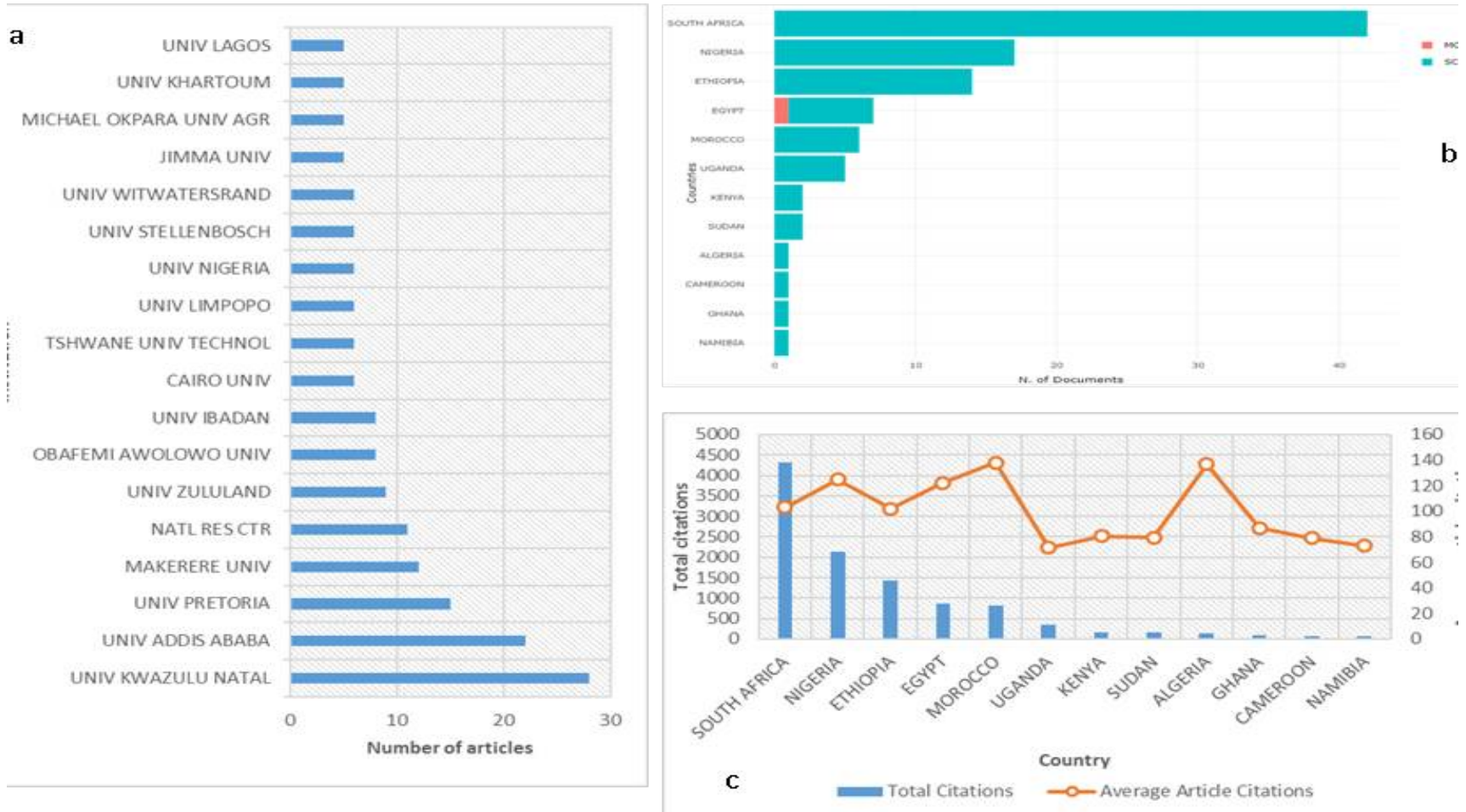

Fig. 4. Most relevant institutions and countries. Most relevant institutions (a), single country publication and multiple country publication (b), countries' citation on African medicinal plant research articles.

literature will explore specific keywords in searching whereas intermediate keywords are commonly used by researchers when they are interested in something that does not belong to a particular theme but within a particular area of interest. On the contrary, general keywords are explored when a researcher is interested in a subject, but a particular thing could be found in different disciplines. Therefore, it is highly imperative for researchers to use appropriate keywords that are within the title, abstract, or main text of their papers to increase the visibility of their published papers. Furthermore, "keyword selection aims to facilitate the efficient retrieval of text content for readers (51). As fundamental tools for indexing databases, they act as a gateway to text. In spite of this critical functionality, many authors undervalue this scientific writing stage. Selecting the most salient keywords significantly increases the chances of a document being retrieved by an article's most pertinent readers, and consequently, help promote an article's visibility within the publication's iceberg".

In the present study, keywords analyses were evaluated for the top 100 most cited papers on African medicinal plant research. In the scientific communications on medicinal plants, authors were used two types of keywords viz., author's keywords and keywords Plus. Thus, in the present analysis, the number of occurrences of above said keywords were determined (Fig. 5). The keywords such as extracts occurred 12 times, antibacterial activity (7 times), extract (7 times), in vitro (7 times) district (6 times), drugs (6 times), flavonoids (6 times), phenolic compounds (5 times) and antioxidant activity (4 times) (Supplementary Table S3). Likewise, for author's keywords, we found a similar occurrence such that medicinal plants occurred 34 times in the whole documents, ethnobotany was used 12 times, medicinal (10 times), South Africa (10 times), plants (9 times), antibacterial (6 times), ethnobotanical survey (6 times), traditional medicine (5), anti-inflammatory (4) etc. (Supplementary Table S4).

There are certain things that researchers should take note of when using keywords in a paper. For example, they should try to avoid using new phrases, terminologies, unnecessary abbreviations, or even local slangs that would not increase the visibility of their papers. It is important to note that editors of some journals have forbidden the use of keywords that do not form either an integral part of the title, abstract, or the main text of the paper. Nevertheless, the strategic choice of keywords should consider the synonymy of the content in the body of the text. It becomes the repetition of something existing. Scientific paper publication moves science because new research evolves from previous ones i.e., they are based on previous research to reaffirm, question, or refute them. Several researchers have explored keywords analyses for bibliometric reviews (66-68).

\section{Authors' collaboration network}

The research collaboration that exists among the researchers that authored the 100 most cited articles on African medicinal plant research was studied. Data visualization and bibliometric mapping are invaluable tools for detecting and analyzing current and potential collaborative research (49). Bibliometric maps and visualization methods were made using VoSviewer software (69). As highlighted in one report (64), "a co-authorship network identifies the number of publications co-authored by at least two researchers". Co-authoring publications 

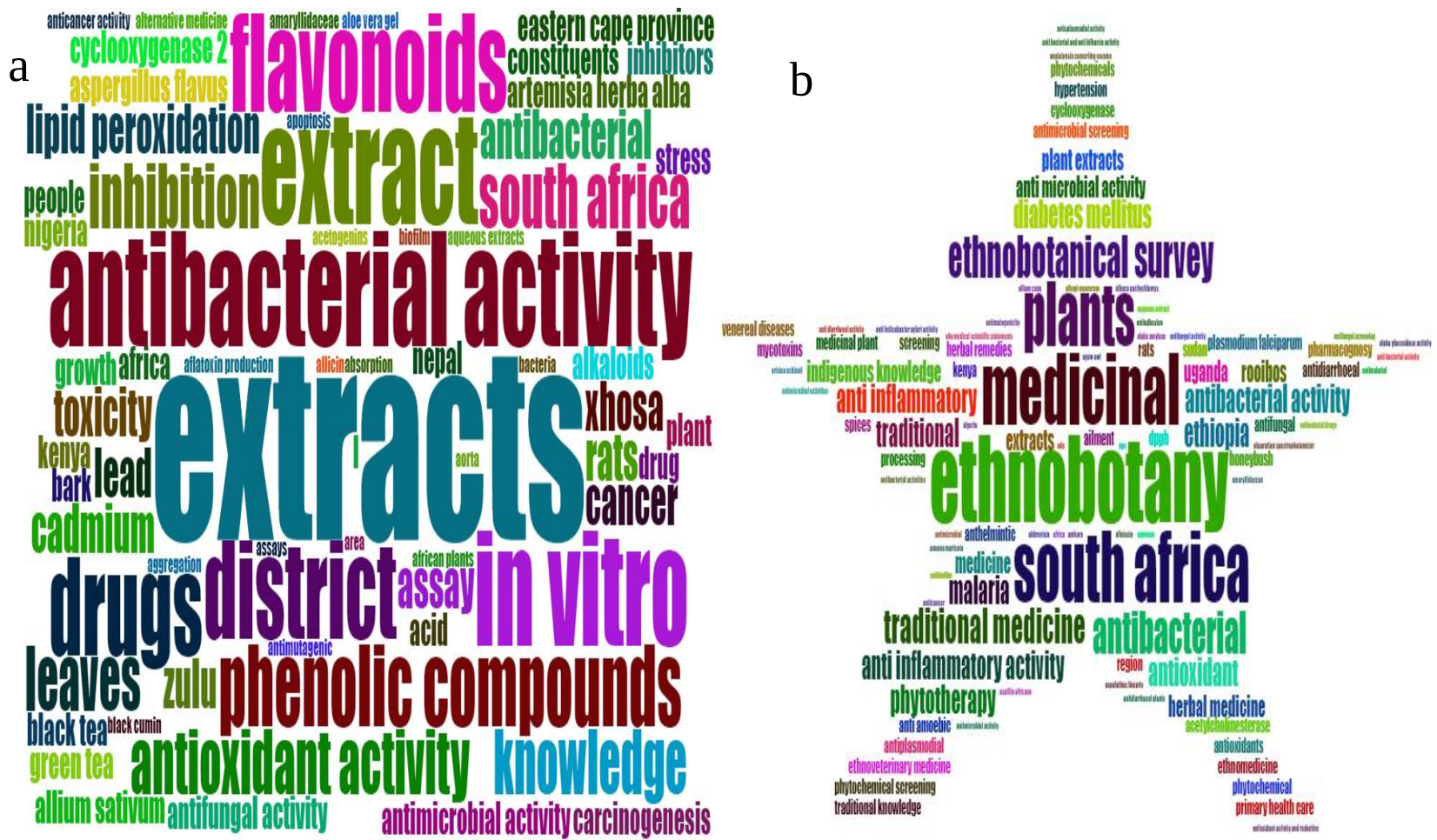

Fig. 5. Keywords Plus (a) and author's keywords (b) on most cited articles on African medicinal plant research.

have critical significance for promoting research innovation and knowledge sharing, as well as improving the research quality (50). In the present study, fractional counting method of analysis in VOSviewer software was selected and 25 was set for the maximum number of authors per document and we reduced the first names of authors to their initials. Subsequently, we reduced the minimum number of documents of authors to be 1 because when set at 5, only 3 authors met the thresholds and used 1 instead. The 5 topmost authors were Van Staden J "(16 documents, 1606 citations, 16 total link strength)", Jager A "(7 documents, 982 citations, 7 total link strength)", Giday M “(4 documents, 576 citations, 4 total link strength)", Joubert E "(4 documents, 330 citations, 4 total link strength)", Teklehaymanot $\mathrm{T}$ "(5 documents, 601 citations, 4 total link strength)" (Fig. 5a). An overall of 302 items was grouped into 63 clusters with 632 links and 181 total link strength. From the results, it is wise to say that authors located within or close to a large cluster have a higher number of co-authors which is suggestive of research collaboration. As emphasized in a report, "density visualization of co-authorships using authors as a unit of the analysis show that coauthorships were high and common among most prolific authors (35). Co-authorships suggest domestic and international collaboration. Authors who were remotely located from clusters have relatively fewer co-authorships and collaborations". Therefore, it is worth noticing in the present study that the position of the researchers on the published papers is the criterion used to determine the most active ones. The WoS database only counts the total number of papers that are associated with the researchers. Hence, the controversial debate concerning the first and last author analysis is less important in this study. The map depicted in 5a revealed several clusters of items that indicate a remarkable collaboration network that exists between the researchers that published these articles under study and this agrees with the collaboration index of 3.01 depicted in Table 1 . However, this map does not show that whether collaboration is national or international. Differentiating the collaboration that exists among the researchers either within the group or within the network is challenging because this analysis cannot distinguish the collaboration type (70).

Similarly, Fig $5 \mathrm{~b}$ depicts the density visualization of the authors and where the deep yellow colour, shows that high collaboration exists between the authors (49); and we observed the cluster within Van Staden J to be highest and this could be responsible for the highest number of publications affiliated to him. The colour of each author shows his or her active year as highlighted by the indicator bar at the corner. According to one report, "research has progressed through three ages: the individual, the institutional and the national, and is now entering a fourth age driven by international collaborations between elite research groups (71). Furthermore, group members can be connected to various networks". One of the major reasons why a research group outputs can be stable over the year is that, member of a group can move to another institution or country and still maintained a good working relationship with the leader or colleagues of his/her former group (72). This collaboration idea brings about increase research productivity (73).

\section{Institutions and countries collaboration networks}

The collaboration that exists between institutions and countries on 100 most cited articles on African 
medicinal plant research was investigated. For the institutional collaboration, we explored the fractional counting method in VOSviewer in which 25 was chosen as the maximum number of institutions per document. We set the minimum number of documents of an institution to be 1 . The top 5 institutions were University of Ibadan "(6 documents, 571 citations, 6 total link strength)”, University of Addis Ababa "(11 documents, 1190 citations, 4 total link strength)", University of Pretoria “(8 documents, 662 citations, 4 total link strength)”, University of Zululand "(5 documents, 577 citations, 4 total link strength)”, University of KwaZulu-Natal "(4 documents, 428 citations, total link strength)”. The 86 items had 82 links with 50 total link strength. Collaboration network among those universities clustering was observed around the University of Pretoria (Fig. 6a) and the collaboration network in the field could be the type that exists among researchers within the same university due to the availability of all the resources needed for the research and not necessarily collaborating with other researchers outside the institution for mutual benefits. Fig. $6 \mathrm{~b}$ depicts the density visualization of institutions, the deep yellow denotes the high collaboration among the institutions, and on the other hand, light yellow signifies low collaboration network that exists between the institutions (49).

Similarly, countries collaboration among the researchers that authored the top 100 most cited articles on African medicinal plant research was evaluated using the fractional counting method in VOSviewer and 25 was used for the maximum number of countries per document. Thereafter, we reduced the minimum number of documents of a country to 1 and 12 countries met the thresholds. These countries are Egypt "(7 documents, 856 citations, 1 total link strength)”, Kenya “(3 documents, 223 citations, 1 total link strength)”, Algeria “(1 document, 137 citations)", Cameroon "(1 document, 79 citations)", Ethiopia “(13 documents, 1355 citations)", Ghana "(1 document, 87 citations)", Morocco “(6 documents, 828 citations)”, Nigeria “(17 documents, 4069 citations)”, South Africa "(41 documents, 4069 citations)", Sudan “(2 documents, 159 citations)”, Uganda “(5 documents, 357 citations)”. Surprisingly, international collaboration was lacking among researchers that authored the selected articles (Fig. 6c). There is no single cluster that exists among these African countries and thus, creating an enormous research gap that needed urgent attention in the field. The researchers can benefit several advantages from international collaboration and we believe that the citation of a publication can be increased by international collaboration as this would increase the visibility of the publication. Over time, the old academic staff has dominated the medicinal plant research and the category of people is less inclined as compared to their younger counterparts to start an international collaboration and they limit their research work within their group (74). As documented by Kyvik and Reymert (75) "the most likely explanation is that younger academic staff are more cosmopolitan in their research orientation due to generational differences in socio-cultural influences and socialization processes at different points in time”. It is paramount to note that most pharmaceutical industries depend on the active ingredients in plants as raw materials for drug development (76). Limited access of people in the developing countries to synthetic drugs coupled with a low standard of living of these people have diverted their attention to the use of cost-effective herbal folklore for the treatment of various human diseases. The availability nature of these plants has made them to be accessible and serves as an alternative to synthetic drugs (77).

\section{Conclusion}

In the present study, a bibliometric analysis was performed to review the top 100 most cited articles on African medicinal plant research over 30 years from 1990 to 2019 focusing on those articles written in English and indexed in SCI-Expanded. The most relevant authors were Van Staden J, Jager AK, and Teklehaymanot $\mathrm{T}$. The top 3 journals are Journal of Ethnopharmacology, Journal of Ethnobiology and Ethnomedicine, South African Journal of Botany. Similarly, most cited journals are Journal of Ethnopharmacology, Phytochemistry, Phytotherapy Research. The most active institutions were the University of KwaZulu-Natal, University of Addis Ababa, and Pretoria while South Africa, Nigeria and Ethiopia were the most cited country. The keywords identified in this study revealed the hotspots of research and research trends that could predict future research in the field. Authors and institutions' collaborations were witnessed among the researchers within each country that led to the relatively high single country publication and the low multiple country publication among the researchers might have affected the outputs and citations as international collaboration was lacking among the researchers that published the articles under investigation. Therefore, multiple countries collaboration should be a focus of social networks among the researchers in the field.

\section{Study limitations}

The bibliometric analysis carried out in the present study has several advantages; however, it is important to highlight some limitations associated with this review. WoS database was used to retrieve data and articles written in English were selected with SCI-Expanded indexing without considering published articles from other databases such as Scopus, PubMed and those non-English written articles and those from other WoS indexes and this might not represent the holistic articles on the subject. Besides, the keywords explored for the search strategy might not represent all the keywords commonly used in the field. Sometimes, the names of medicinal plants are commonly written in their scientific names in the article title; and it is not possible to identify or include all the scientific names of the African plants that have been validated scientifically for therapeutic uses in our search query, hence, our analysis might have excluded some articles on the subject that could affect the accuracy of the analysis somehow. Finally, citations analysis was evaluated but old articles would have more 


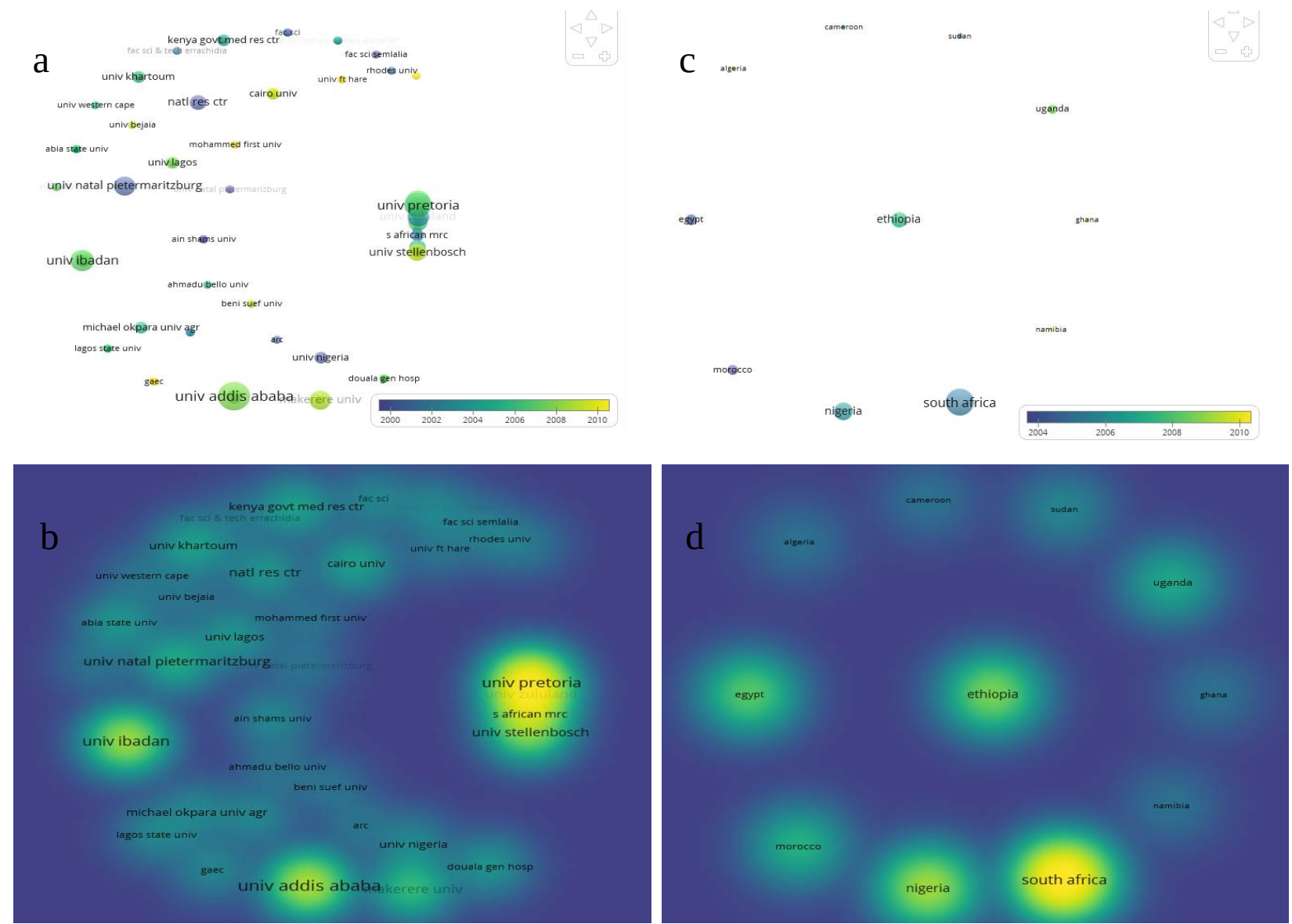

Fig. 6. Institutions and countries' collaboration networks of 100 most cited articles on African medicinal plant research. Overlay visualization network (a and c), density visualization network (b and d).

citations than the recently published ones, hence, the bias and influence of different publication year on article citation cannot be removed in the analysis, however, it is paramount to note that analysis in the present study was based on WoS information.

\section{Acknowledgements}

The authors duly acknowledge Cape Peninsula University of Technology for the financial support.

\section{Authors' contributions}

Conceptualization, KO and 000; resources, OOO; writing - original draft preparation, KO; writing review and editing, KO and OOO; supervision - OOO; project administration, 000; funding acquisition, OOO. Both authors have read and agreed to the published version of the manuscript.

\section{Conflict of interests}

Authors do not have any conflict of interests to declare.

\section{References}

1. World Health Organization. Traditional Medicines. 2008. Available from: http://who.int/mediacentre/factsheets/fs134/en/ [Accessed: November 26, 2020]
2. Joubert E, De Beer D, Malherbe CJ. Herbal teas-Exploring untapped potential and strengthening commercialisation South African Journal of Botany. 2017(110):1-3. https://doi.org/ 10.1016/j.sajb.2017.01.204

3. Chintamunnee V, Mahomoodally MF. Herbal medicine commonly used against non-communicable diseases in the tropical island of Mauritius. Journal of Herbal Medicine. 2012;2(4):113-25. https://doi.org/10.1016/j.hermed.2012.06.001

4. Ayeni G, Pooe OJ, Singh M, Nundkumar N, Simelane MB Cytotoxic and antioxidant activities of selected South African medicinal plants. Pharmacognosy Journal. 2019;11(6s). https:// doi.org/10.5530/pj.2019.11.234

5. Salehi B, Kumar NV, Sener B, Sharifi-Rad M, Kılıç M, Mahady GB, Vlaisavljevic S, Iriti M, Kobarfard F, Setzer WN, Ayatollahi SA. Medicinal plants used in the treatment of human immunodeficiency virus. International Journal of Molecular Sciences. 2018;19(5):1459. https://doi.org/10.3390/ijms19051459

6. Calapai G. European legislation on herbal medicines. Drug Safety. 2008;31(5):428-31. https://doi.org/10.2165/00002018200831050-00009

7. Zhou X, Seto SW, Chang D, Kiat H, Razmovski-Naumovski V, Chan K, Bensoussan A. Synergistic effects of Chinese herbal medicine: A comprehensive review of methodology and current research. Frontiers in Pharmacology. 2016;7:201. https://doi.org/10.3389/fphar.2016.00201

8. Mahomoodally MF. Traditional medicines in Africa: an appraisal of ten potent African medicinal plants. EvidenceBased Complementary and Alternative Medicine. 2013;2013. https://doi.org/10.1155/2013/617459

9. Bandaranayake WM. Quality control, screening, toxicity and regulation of herbal drugs. Modern Phytomedicine. 2006;25-57. https://doi.org/10.1002/9783527609987.ch2

10. Kong JM, Goh NK, Chia LS, Chia TF. Recent advances in traditional plant drugs and orchids. Acta Pharmacologica Sinica. 2003;24(1):7-21 
11. Agyare C, Boakye YD, Bekoe EO, Hensel A, Dapaah SO, Appiah T. African medicinal plants with wound healing properties. Journal of Ethnopharmacology. 2016;177:85-100. https://doi.org/10.1016/j.jep.2015.11.008

12. Mailu JK, Nguta JM, Mbaria JM, Okumu MO. Medicinal plants used in managing diseases of the respiratory system among the Luo Community: An appraisal of Kisumu East Sub-County, Kenya.

13. Ekor M, Osonuga OA, Odewabi AO, Bakre AG, Oritogun KS. Toxicity evaluation of Yoyo 'cleanser'bitters and fields Swedish bitters herbal preparations following sub-chronic administration in rats. Am J Pharmacol Toxicol. 2010;5:159-66. https://doi.org/10.3844/ajptsp.2010.159.166

14. Kasilo OM, Trapsida JM. Decade of African traditional medicine, 2001-2010. Afr Health Mon. (Special Issue). 2011;14:25-31.

15. Elgazar AA, Selim NM, Abdel-Hamid NM, El-Magd MA, El Hefnawy HM. Isolates from Alpinia officinarum Hance attenuate LPS-induced inflammation in HepG2: Evidence from in silico and in vitro studies. Phytotherapy Research. 2018;32(7):1273-88. https://doi.org/10.1002/ptr.6056

16. Xie S, Zhou J. Harnessing plant biodiversity for the discovery of novel anticancer drugs targeting microtubules. Frontiers in Plant Science. https://doi.org/10.3389/fpls.2017.00720

2017;8:720.

17. Anquez-Traxler C. The legal and regulatory framework of herbal medicinal products in the European Union: a focus on the traditional herbal medicines category. Drug Information Journal. https://doi.org/10.1177/009286151104500102 2011;45(1):15-23.

18. Ekor M. The growing use of herbal medicines: issues relating to adverse reactions and challenges in monitoring safety. Frontiers in Pharmacology. 2014;4:177. https://doi.org/10.3389/fphar.2013.00177

19. Rinaldi M, Micali A, Marini H, Adamo EB, Puzzolo D, Pisani A, Trichilo V, Altavilla D, Squadrito F, Minutoli L. Cadmium, organ toxicity and therapeutic approaches: a review on brain, kidney and testis damage. Current Medicinal Chemistry. 2017;24(35):3879-93.

https://doi.org/10.2174/0929867324666170801101448

20. Finkel T, Holbrook NJ. Oxidants, oxidative stress and the biology of ageing. Nature. 2000;408(6809):239-47. https://doi.org/10.1038/35041687

21. Gutteridge JM, Halliwell B. The measurement and mechanism of lipid peroxidation in biological systems. Trends in Biochemical Sciences. 1990;15(4):129-35. https://doi.org/10.1016/0968-0004(90)90206-Q

22. Hassan SW, Ayeni G, Wasagu RSU, Umar RA, Agaie BM, Farouk UZ. Research paper hepatoprotective effect of leaf extracts of Newbouldia laevis on carbon tetrachloride-intoxicated rates. J Glob Biosci. 2015;4(5):2258-81.

23. Crouch N, Symmonds R, Spring W, Diederichs N. Facts sheets for growing popular medicinal plant species in Commercialising Medicinal Plants-A Southern African Guide, N. Diederichs, Ed., pp. 97-142, Sun Press, Stellenbosch, South Africa, 2006.

24. Lis-Balchin M, Hart S, Simpson E. Buchu (Agathosma betulina and A. crenulata, Rutaceae) essential oils: their pharmacological action on guinea-pig ileum and antimicrobial activity on microorganisms. Journal of Pharmacy and Pharmacology. https://doi.org/10.1211/0022357011775703

25. Joubert E, Gelderblom W.C.A, Louw A, de Beer D. South African herbal teas: Aspalathus linearis, Cyclopia spp. and Athrixia phylicoides-a review. Journal of Ethnopharmacology. 2008;119(3):376-412. https://doi.org/10.1016/j.jep.2008.06.014

26. Barnes J. Devil's claw (Harpagophytum procumbens). Also known as "grapple plant" or "wood spider" Journal of Primary Health Care. 2009;1(3):238-39. https://doi.org/10.1071/HC09238

27. Viljoen AM, Demirci B, Başer KHC, Van Wyk BE. The essential oil composition of the roots and rhizomes of Siphonochilus aethiopicus. South African Journal of Botany. 2002;68(1):11516. https://doi.org/10.1016/S0254-6299(15)30453-1
28. Mills E, Cooper C, Seely D, Kanfer I. African herbal medicines in the treatment of HIV: hypoxis and Sutherlandia. An overview of evidence and pharmacology. Nutrition Journal. 2005;4(19) 1-8. https://doi.org/10.1186/1475-2891-4-19

29. Lyu QJ, Pu QH, Zhang J. Bibliometric analysis of scientific publications in endocrinology and metabolism from China, Japan and South Korea. Scientometrics. 2017;110(1):105-12. https://doi.org/10.1007/s11192-016-2179-8

30. Pei W, Peng R, Gu Y, Zhou X, Ruan J. Research trends of acupuncture therapy on insomnia in two decades (from 1999 to 2018): a bibliometric analysis. BMC Complementary and Alternative Medicine. 2019;19(1):225. https://doi.org/10.1186/s12906-019-2606-5

31. Zou X, Yue WL, Le Vu H. Visualization and analysis of mapping knowledge domain of road safety studies. Accident Analysis and Prevention. 2018;118:131-45. https://doi.org/10.1016/j.aap.2018.06.010

32. Ekinci S, Agilli M, Ersen O, Ekinci GH. Letter to the editor regarding analysis of changing paradigms of management in 179 patients with spinal tuberculosis during a 12-year period and proposal of a new management algorithm. World Neurosurgery. https://doi.org/10.1016/j.wneu.2014.12.003

2014;84(6):2072.

33. Gao Y, Wang Y, Zhai X, He Y, Chen R, Zhou J, Li M, Wang Q. Publication trends of research on diabetes mellitus and $\mathrm{T}$ cells (1997-2016): A 20-year bibliometric study. PLoS One. 2017;12(9):e0184869

https://doi.org/10.1371/journal.pone.0184869

34. Geaney F, Scutaru C, Kelly C, Glynn RW, Perry IJ. Type 2 diabetes research yield, 1951-2012: bibliometrics analysis and density-equalizing mapping. PloS One. 2015;10(7):e0133009. https://doi.org/10.1371/journal.pone.0133009

35. Sweileh WM, Al-Jabi SW, Sawalha AF, Sa'ed HZ. Bibliometric profile of the global scientific research on autism spectrum disorders. Springerplus. 2016;5(1):1480. https://doi.org/10.1186/ s40064-016-3165-6

36. Nafade V, Nash M, Huddart S, Pande T, Gebreselassie N, Lienhardt C, Pai M. A bibliometric analysis of tuberculosis research, 2007-2016. PloS One. 2018;13(6):e0199706. https://doi.org/10.1371/journal.pone.0199706

37. Liu X, Liu N, Zhou M, Lu Y, Li F. Bibliometric analysis of global research on the rehabilitation of spinal cord injury in the past two decades. Therapeutics and Clinical Risk Management. 2019;15:1. https://doi.org/10.2147/TCRM.S163881

38. Sharma N, Bairwa M, Gowthamghosh B, Gupta SD, Mangal DK A bibliometric analysis of the published road traffic injuries research in India, post-1990. Health Research Policy and Systems. 2018;16(1):18. https://doi.org/10.1186/s12961-0180298-9

39. Fu H, Hu T, Wang J, Feng D, Fang H, Wang M, Tang S, Yuan F, Feng Z. A bibliometric analysis of malaria research in China during 2004-2014. Malaria Journal. 2015;14(1):195. https://doi.org/10.1186/s12936-015-0715-2

40. Garrido-Cardenas JA, Cebrián-Carmona J, González-Cerón L, Manzano-Agugliaro F, Mesa-Valle C. Analysis of global research on Malaria and Plasmodium vivax. International Journal of Environmental Research and Public Health. 2019;16(11):1928. https://doi.org/10.3390/ijerph16111928

41. Kolle SR, Shankarappa TH. Publication trends in food-borne disease research (1991-2015): a web of science core collection based analysis. Journal of Agricultural and Food Information. 2017;18(1):53-63. https://doi.org/10.1080/10496505.2016.1261030

42. Zhang C, Fang Y, Chen X, Congshan T. Bibliometric analysis of trends in global sustainable livelihood research. Sustainability. 2019;11(4):1150. https://doi.org/10.3390/su11041150

43. Ekundayo TC, Okoh AI. A global bibliometric analysis of Plesiomonas-related research (1990-2017). PloS One. 2018;13(11):e0207655. https://doi.org/10.1371/journal.pone.0207655

44. Igere BE, Ekundayo TC. Global mapping of cholera vibrio and outbreaks in the Pre-Millennium Development Goals (MDG)/ Sustainable Development Goals (SDG) and MDGs/SDGs era of 
1990-2019. Microbial Pathogenesis. 2020;149:104319. https://doi.org/10.1016/j.micpath.2020.104319

45. Barbosa FG, Schneck F. Characteristics of the top-cited papers in species distribution predictive models. Ecological Modelling. 2015;313:77-83. https://doi.org/10.1016/j.ecolmodel.2015.06.014

46. Zhi W, Ji G. Constructed wetlands, 1991-2011: a review of research development, current trends and future directions. Science of the Total Environment. 2012;441:19-27. https://doi.org/10.1016/j.scitotenv.2012.09.064

47. Lu C, Bing Z, Bi Z, Liu M, Lu T, Xun Y, Wei Z, Yang K. Top-100 most cited publications concerning network pharmacology: a bibliometric analysis. Evidence-Based Complementary and Alternative Medicine. https://doi.org/10.1155/2019/1704816

48. Mo Z, Fu HZ, Ho YS. Highly cited articles in wind tunnel-related research: a bibliometric analysis. Environmental Science and $\begin{array}{lll}\text { Pollution 2018;25(16):15541-53 } & \end{array}$ https://doi.org/10.1007/s11356-018-1766-z

49. Orimoloye IR, Ololade OO. Global trends assessment of environmental health degradation studies from 1990 to 2018. Environment, Development and Sustainability: A Multidisciplinary Approach to the Theory and Practice of Sustainable Development. https://doi.org/10.1007/s10668-020-00716-y

50. Mao X, Chen C, Wang B, Hou J, Xiang C. A global bibliometric and visualized analysis in the status and trends of subchondral bone research. Medicine. 2020;99(22):e20406. https://doi.org/10.1097/MD.0000000000020406

51. Garcia DC, Gattaz CC, Gattaz NC. The relevance of title, abstract and keywords for scientific paper writing. Revista de Administração Contemporânea. 2019;23(3):I-XVIII. https://doi.org/10.1590/1982-7849rac2019190178

52. Aksnes DW, Langfeldt L, Wouters P. Citations, citation indicators and research quality: An overview of basic concepts and theories. Sage Open. 2019;9(1):2158244019829575. https://doi.org/10.1177/2158244019829575

53. Yuan H, Ma Q, Ye L, Piao G. The traditional medicine and modern medicine from natural products. Molecules. 2016;21(5):559. https://doi.org/10.3390/molecules21050559

54. Ge YB, Cheng XZ, Yan AL, Xu J. Research progress of anti-tumor mechanism of paeoniflorin. Journal of Chinese Medicinal Materials. 2015;38:636-39.

55. Gong QH, Shi JS, Yang DL, Huang B, Xie XL. Pharmacological actions and its mechanisms of gastrodin in central nervous system. Chin J New Drugs Clin Rem. 2011;30(3):176-79.

56. Wei H, Peng Y, Ma GX, Xu LJ, Xiao PG. Advances in studies on active components of Saussurea lappa and their pharmacological actions. Chinese Traditional and Herbal Drugs. 2012;43(3):613-20.

57. Zhao P, Niu J, David YW, Wang J, Sun Y, Li Y. Effect and mechanism of traditional Chinese medicine and their active constituents in postmenopausal osteoporosis. Zhongguo Zhong yao za zhi= Zhongguo zhongyao zazhi= China Journal of Chinese Materia Medica. 2012;37(12):1693-9.

58. Bartneck C, Kokkelmans S. Detecting h-index manipulation through self-citation analysis. Scientometrics. 2011;87(1):85-98. https://doi.org/10.1007/s11192-010-0306-5

59. Bornmann L, Daniel HD. The state of $h$ index research: is the $h$ index the ideal way to measure research performance?. EMBO Reports. 2009;10(1):2-6. https://doi.org/10.1038/embor.2008.233

60. Hirsch JE. An index to quantify an individual's scientific research output. Proceedings of the National Academy of Sciences. https://doi.org/10.1073/pnas.0507655102 2005;102(46):16569-72.
61. Bertoli-Barsotti L, Lando T. A theoretical model of the relationship between the h-index and other simple citation indicators. Scientometrics. 2017;111(3):1415-48. https://doi.org/ 10.1007/s11192-017-2351-9

62. Paiva CE, Lima JP, Paiva BS. Articles with short titles describing the results are cited more often. Clinics. 2012;67(5):509-13. https://doi.org/10.6061/clinics/2012(05)17

63. Aguinis H, Suárez-González I, Lannelongue G, Joo H. Scholarly impact revisited. Academy of Management Perspectives 2012;26(2):105-132. https://doi.org/10.5465/amp.2011.0088

64. Kamdem JP, Duarte AE, Lima KR, Rocha JB, Hassan W, Barros LM, Roeder T, Tsopmo A. Research trends in food chemistry: A bibliometric review of its 40 years anniversary (1976-2016) Food chemistry. 2019;294:448-57. https://doi.org/10.1016/j.foodchem.2019.05.021

65. Lebrun JL. Scientific writing: A reader and a writer's guide. 2007. Boston, MA: World Scientific. https://doi.org/10.1142/6286

66. Huang L, Shi X, Zhang N, Gao Y, Bai Q, Liu L, Zuo L, Hong B. Bibliometric analysis of trends and issues in traditional medicine for stroke research: 2004-2018. BMC Complementary Medicine and Therapies. 2020;20(1):1-10. https://doi.org/10.1186/s12906-020-2832-x

67. Su B, Guan Q, Yu S. The neurotoxicity of nanoparticles: a bibliometric analysis. Toxicology and Industrial Health 2018;34(12):922-29. https://doi.org/10.1177/0748233718804973

68. Qi Y, Chen X, Hu Z, Song C, Cui Y. Bibliometric analysis of algalbacterial symbiosis in wastewater treatment. Internationa Journal of Environmental Research and Public Health 2019;16(6):1077. https://doi.org/10.3390/ijerph16061077

69. Van Eck NJ, Waltman L. Software survey: VOSviewer, a computer program for bibliometric mapping. Scientometrics. 2010;84(2):523-38. https://doi.org/10.1007/s11192-009-0146-3

70. Newman ME. The structure of scientific collaboration networks. Proceedings of the national academy of sciences. 2001;98(2):404-49. https://doi.org/10.1073/pnas.98.2.404

71. Adams J. Collaborations: The rise of research networks. Nature. 2012;490:335-36. https://doi.org/10.1038/490335a

72. Jacob M, Meek VL. Scientific mobility and international research networks: trends and policy tools for promoting research excellence and capacity building. Studies in Higher Education. https://doi.org/10.1080/03075079.2013.773789

73. Guimera R, Uzzi B, Spiro J, Amaral LA. Team assembly mechanisms determine collaboration network structure and team performance. Science. 2005;308(5722):697-702. https://doi.org/10.1126/science.1106340

74. Kyvik S, Olsen T. Does the aging of tenured academic staff affect the research performance of universities? Scientometrics. 2008;76(3):439-55. https://doi.org/10.1007/s11192-007-1767-z

75. Kyvik S, Reymert I. Research collaboration in groups and networks: differences across academic fields. Scientometrics. 2017;113(2):951-67. https://doi.org/10.1007/s11192-017-2497-5

76. Arceusz A, Radecka I, Wesolowski M. Identification of diversity in elements content in medicinal plants belonging to different plant families. Food Chemistry. 2010;120(1):52-58. https://doi.org/10.1016/j.foodchem.2009.09.068

77. Salmerón-Manzano E, Manzano-Agugliaro F. Worldwide Research on Low Cost Technologies through Bibliometric Analysis. Inventions. https://doi.org/10.3390/inventions5010009
2020;5(1):9. 